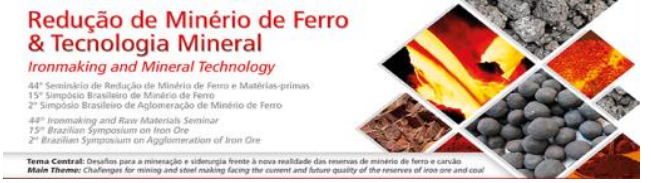

\title{
DESENVOLVIMENTO E IMPLANTAÇÃO DE SOLUÇÃO ANALÍTICA PARA O PLANEJAMENTO OTIMIZADO E INTEGRADO DA CADEIA DE REDUTORES DA CSN*
}

\section{Resumo}

Sidiney Nascimento Silva ${ }^{1}$ Agenor Medrado da Silva² Aline Aguiar Lopes ${ }^{3}$ Anderson Soares da Silva ${ }^{3}$ Cristiano de Oliveira Neville ${ }^{3}$ Eduardo Medeiros Milane ${ }^{4}$ Daniela Tassinari Miranda ${ }^{5}$ Volnei dos Santos ${ }^{6}$

Em parceria com a UniSoma, empresa especializada em soluções analíticas baseadas em otimização, a CSN desenvolveu e implantou uma solução sob medida para o planejamento de sua cadeia de redutores. A solução é composta por dois módulos básicos - Embarque ${ }^{\circledR}$ e MIX®, que dão suporte às decisões de caráter tático-operacional relativas à cadeia de abastecimento de combustíveis sólidos, abrangendo desde a aquisição das matérias-primas até o seu consumo nos vários processos siderúrgicos -coqueria, altos-fornos e sinterização. O Módulo Embarque ${ }^{\circledR}$, tático, possui uma "inteligência computacional", na forma de um modelo matemático, que trata, de forma integrada, três subproblemas correlacionados: a programação do abastecimento, o planejamento de mistura e de produção, dos vários processos, e o planejamento de estocagem ao longo do tempo. O modelo fornece soluções de compromisso entre os objetivos de custo e qualidade. O Módulo MIX®, otimizador operacional, é usado para definir a programação das misturas a serem realizadas no curto prazo. O trabalho apresenta não apenas os aspectos técnicos da solução, mas também os desafios enfrentados durante a sua implantação e os resultados percebidos com a sua utilização.

Palavras-chave: Abastecimento; Redutores; Mistura de Carvões; Pesquisa Operacional; Modelo de Programação Matemática.

\section{DEVELOPMENT AND IMPLEMENTATION OF AN ANALYTICAL SOLUTION FOR CSN'S Abstract OPTIMIZED AND INTEGRATED PLANNING OF REDUCTANTS SUPPLY CHAIN}

In partnership with UniSoma, a company focused on analytical solutions development based on optimization, CSN has developed and implemented a tailor made computacional solution for the planning of its reductants supply chain. The solution consists of two basic modules - Embarque ${ }^{\circledR}$ and MIX®, which give support for the tactical and operational decisions regarding the solid fuels supply chain, ranging from the raw material acquisition until its consumption in the various steelmaking processes - Coke Plant, Blast Furnaces and Sinter Plant. Embarque® Module, tactical one, has a "computational intelligence" - in the form of a mathematical model - to solve in an integrated manner three related subproblems: the supply scheduling, the blending and production planning of various processes and the storage planning over time. The model is able to find a compromised solution between cost and quality objectives. The MIX $\AA$ Module, operational one, is used to define the blending scheduling in the short term, also through the use of an optimization math model. The paper presents not only the technical aspects of the solution as well the challenges faced during its implementation and the results realized since the beginning of its operation.

Keywords: Supply; Reductants; Coals Blending; Operations Research; Mathematical Programming Modell.

1 Engenheiro Civil, Doutor em Ciência e Engenharia de Materiais, Gerente de Processos da Metalurgia, Companhia Siderúrgica Nacional (CSN), Volta Redonda, RJ, Brasil.

2 Engenheiro Metalúrgico, Doutor em Engenharia Metalúrgica, Engenheiro Especialista, CSN, Volta Redonda, RJ, Brasil.

3 Engenheira Metalúrgica, UFF, Companhia Siderúrgica Nacional, Volta Redonda, RJ, Brasil.

4 Graduada em Matemática Aplicada e Computacional, Sócia da UniSoma Computação Ltda., Campinas, SP, Brasil.

5 Eng. de Mecânica Aeronáutica, Mestre em Engenharia Elétrica, Sócio da UniSoma Computação Ltda., Campinas, SP, Brasil.

6 Engenheiro de Computação, Sócio da UniSoma Computação Ltda., Campinas, SP, Brasil. 


\section{INTRODUÇÃO}

Os redutores utilizados na produção de coque devem possuir propriedades físicas, químicas e metalúrgicas compatíveis com as exigências dos processos de coqueificação e de redução em altos-fornos em termos da mistura de carvões e da qualidade do coque, respectivamente.

As principais propriedades físicas controladas para a mistura de carvões são a reflectância, fluidez, pressão de coqueificação e dilatação. Os parâmetros de qualidade Reflectância e Fluidez são predominantes no processo de previsão da qualidade metalúrgica do coque. Com relação ao coque, controla-se principalmente o DI (drum index), que mede a resistência às solicitações mecânicas que o coque é submetido no transporte da Coqueria até o Alto-Forno. O segundo parâmetro metalúrgico de grande importância para o processo Alto-Forno é a reatividade do coque. Em termos de propriedades químicas, aquelas comumente controladas são os teores de cinza, matéria volátil, enxofre e fósforo.

Alguns requisitos, tanto do ponto de vista do processo de coqueificação quanto da qualidade do coque, restringem as alternativas de carvões disponíveis mundialmente. Os elevados teores de cinza e enxofre, típicos do carvão mineral nacional, por exemplo, limitam a sua aplicação na siderurgia, em função do impacto sobre os custos de produção. As principais reservas de redutores com qualidade apropriada à aplicação nos processos siderúrgicos encontram-se na América do Norte e Austrália.

O abastecimento de carvões da Usina Presidente Vargas, UPV, localizada em Volta Redonda, RJ, é realizado através de contrato anual, envolvendo diversos fornecedores, dispersos globalmente, mas concentrados, principalmente, na América do Norte e Austrália. O gasto com a aquisição de redutores é, historicamente, o principal componente na matriz dos custos de produção. Nesse contexto, em 1996, a UniSoma desenvolveu para a CSN O PLANCOQUE, ferramenta de suporte à determinação otimizada de sua política anual de compra de carvões, baseada na relação entre o custo e a qualidade dos carvões de cada um de seus potenciais fornecedores. Além de calcular o mix ótimo de compra de carvões, a ferramenta gerava a Curva de Demanda - quantidade comprada $x$ preço de aquisição, que subsidiava as negociações através de parâmetro quantitativo, através do cálculo dos preços "justos" ou de substituição para os carvões de diversas proveniências. Uma vez definido o orçamento de compra anual de redutores, e não apenas de carvões de coqueria, torna-se necessário programar o seu recebimento, visando a garantir o abastecimento dos vários processos - coqueria, sinterização e altos-fornos. No caso particular da CSN, os redutores, provenientes de diversos portos e rotas, são recebidos no porto de Itaguaí, RJ, e estocados nos pátios de armazenagem. Destaca-se que algumas rotas passam por mais de um porto de origem, de forma a viabilizar a formação de cargas combinadas.

As misturas de carvões são planejadas visando a atender o programa de produção (volume) e a qualidade do coque. Portanto, a programação do abastecimento deve ser coerente com as misturas planejadas ao longo do ano, de forma a garantir a produção de coque de acordo com os requisitos técnicos e de qualidade. Em termos práticos, a reprogramação de abastecimento deve então considerar os saldos contratuais existentes de carvões, ainda não transportados, dentro das vigências acordadas.

Além disso, é necessário programar o recebimento de forma a viabilizar a formação de um estoque mínimo de segurança de um mix de carvões tecnicamente apropriado às produções de coque, estoque viável ("misturável"), e de gusa. Esse estoque serve para amortizar o impacto de eventuais variabilidades no processo,

\footnotetext{
* Contribuição técnica ao 44ํㅗㄴ Seminário de Redução de Minério de Ferro e Matérias-primas,

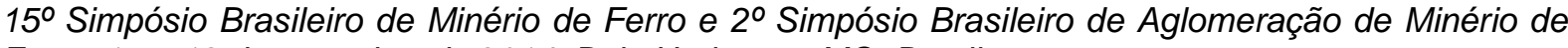
Ferro, 15 a 18 de setembro de 2014, Belo Horizonte, MG, Brasil.
} 
tais como, atrasos no recebimento e desvios na qualidade contratada dos combustíveis

recebidos.

O processo de abastecimento é bastante flexível, conferindo-lhe, por conseguinte, elevada complexidade. Em adição, o abastecimento está diretamente ligado ao problema da mistura dos carvões, tanto do ponto de vista da produção bem como do material em estoque, que por sua vez tem uma flexibilidade ainda maior, a ponto, por exemplo, de um problema de natureza logística, com alguma facilidade, poder ser corrigido por um ajuste na produção. Como consequência, é grande o espaço de alternativas de programação e, portanto, é fundamental a seleção daquelas alternativas de custo mínimo - custo CIF.

O PLANCOQUE dava suporte ao equacionamento dos problemas de natureza estratégica da cadeia de fornecimento de redutores, todavia aqueles de ordem tática e operacional, descritos anteriormente, permaneciam gerenciados simplesmente através do uso de planilhas eletrônicas, sem o ferramental metodológico que viabilizasse suas resoluções de forma otimizada, integrada e automática. Sendo assim, em 2011, a UniSoma e a CSN estabeleceram uma nova parceria para o desenvolvimento e implantação da Solução UniSoma para o Planejamento da Cadeia de Redutores, abrangendo (i) a programação do abastecimento da Usina; (ii) o planejamento e a programação da mistura de carvões e de produção, dos vários processos consumidores de redutores; e (iii) o planejamento de estocagem estratégica, necessária ao enfrentamento das variabilidades intrínsecas aos processos de abastecimento e de produção.

\section{A SOLUÇÃO}

Além do Módulo Estratégico, a Solução é composta por outros dois módulos, objetos da nova parceria de trabalho entre CSN e UniSoma: Embarque® e MIX®. Esses Módulos dão suporte às decisões tático-operacionais, relativas ao planejamento da cadeia de fornecimento de redutores, abrangendo desde a aquisição dos combustíveis até a alimentação dos processos siderúrgicos consumidores coqueria, altos-fornos e sinterizações. O Módulo Embarque®, tático, possui uma "inteligência computacional", na forma de um modelo matemático, que trata, de forma integrada, os três subproblemas que compõem o Problema de Planejamento da Cadeia de Redutores em Usinas integradas: a programação de embarques, o plano de mistura e o plano de estocagem, conforme ilustrado na Figura 1.

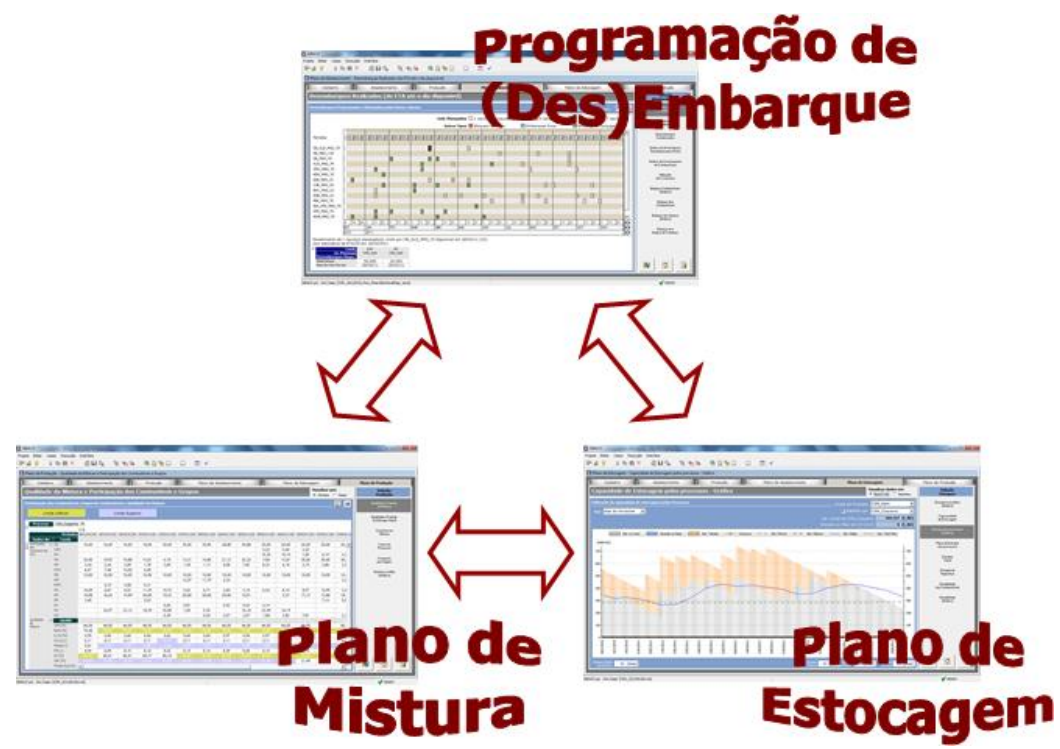

Figura 1: Visão Integrada do Módulo Embarqueß. 
A programação de embarque deve balancear o fornecimento dos diversos redutores ao longo do tempo, visando a garantir a produção dos processos da área de redução - coquerias, altos-fornos e sinterização. Em adição, a programação de embarque deve permitir a formação de estoques mínimos de segurança, como precaução às variabilidades dos processos de fornecimento - os carvões de coqueria em estoque, por exemplo, podem ser utilizados antecipadamente sempre que necessário. Este subproblema de planejamento da estocagem estratégica também está integrado ao de Planejamento da Produção, porque é possível, no curto prazo, alterar a mistura de carvões para acertar a qualidade do coque, utilizando-se carvões planejados para serem consumidos posteriormente. Além disso, é possível "precificar" o custo de formação do estoque de segurança e seu impacto no custo CIF global. Os navios utilizados no transporte de redutores possuem diferentes capacidades, que podem, por sua vez, serem carregados com um ou mais redutores. Condicionantes operacionais como essas fizeram com que o problema relacionado ao Embarque ${ }^{\circledR}$ tenha sido modelado como um problema de Programação Matemática Misto-Inteira, embora estas não sejam as únicas razões. Este modelo considera restrições diversas como, por exemplo, (i) capacidades de estocagem em pátios diversos, segundo custos diferenciados; (ii) a durabilidade dos carvões; (iii) os requisitos de estoque viável, em número de dias; (iv) o número máximo de redutores nas misturas, limitado ao número de dosadores; (v) as capacidades de descarga no porto de Itaguaí; e (vi) os bloqueios de portos e/ou fornecedores - simulação de indisponibilidade para o carregamento na Austrália na época de chuvas, por exemplo. O modelo é capaz ainda de encontrar soluções otimizadas, de acordo com o critério de custo global - custo CIF, abrangendo tanto a composição dos custos diretos, relacionados à cadeia de fornecimento - compra, frete, capital imobilizado, etc., quanto os custos indiretos, que dizem respeito às violações de restrições de atendimento - qualidade, estoque viável, etc., necessárias à obtenção de soluções factíveis. Portanto, a solução final é uma solução de compromisso entre os objetivos custo e qualidade. Esta visão sistêmica do modelo faz com que ele identifique oportunidades de ganhos econômicos, que normalmente não são percebidas no processo de gestão convencional, devido à complexidade do processo, que é bem ilustrada pelos milhares de variáveis e restrições das instâncias típicas de otimização da CSN. Dessa forma, o modelo considera dados de entrada de natureza diversas, tais como, comerciais, de produção e logísticas, conforme ilustrado na Figura 2.

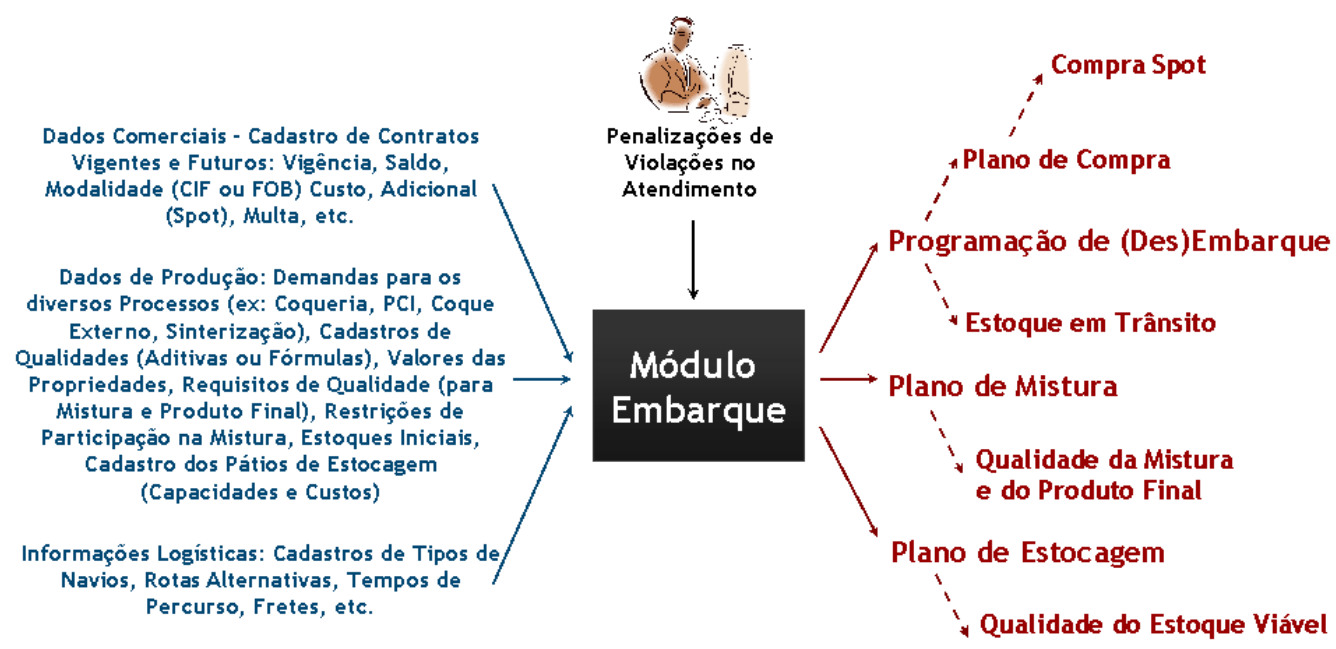

Figura 2: Entradas e Saídas do Módulo Embarque® 
O Módulo $\mathrm{MIX} \circledast$, operacional, é usado para definir a programação de mistura de curto prazo. A programação de mistura obtida, também através do uso de um modelo de otimização, é uma solução de compromisso entre critérios diversos e, muitas vezes, conflitantes, tais como, (i) atendimentos dos requisitos de qualidade e de participação na mistura; (ii) o número de misturas; (iii) o custo da mistura; e (iv) o atendimento da meta de consumo ou plano de mistura, definido no Módulo Embarque $\left.{ }^{\circledR}\right)$, dentre outros. O módulo $\mathrm{MIX} \circledast$ observa ainda aspectos operacionais do processo de mistura como, por exemplo, a mistura inicial e o número máximo de dosadores. A Figura 3 detalha todos os dados de entrada que são considerados pelo Módulo MIX®.

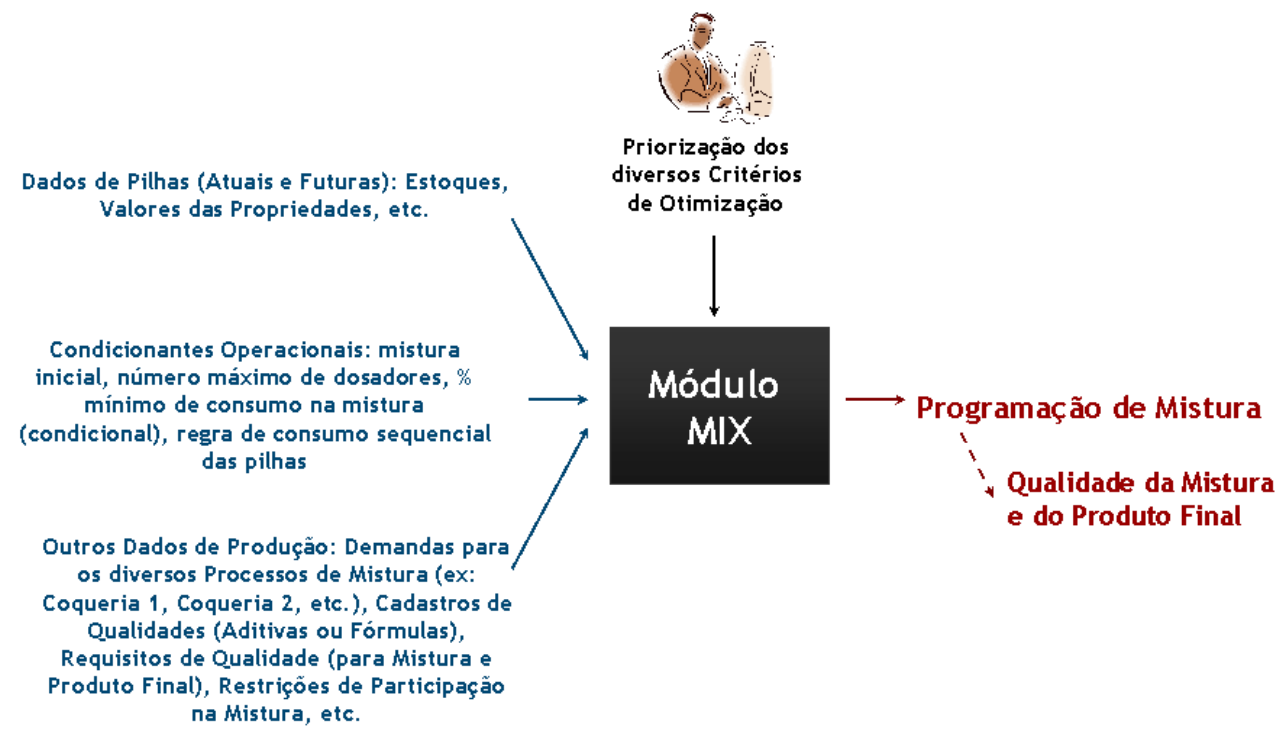

Figura 3: Entradas e Saídas do Módulo MIX®

Vale observar que ambos os Modelos, do ponto de vista do cálculo da mistura, consideram os modelos de previsão de qualidades específicos da CSN - modelos desenvolvidos pelos especialistas da empresa, baseados no histórico de produção. Por conseguinte, o modelo é totalmente aderente à filosofia e aos parâmetros de qualidade da CSN. Durante a fase de implantação foi identificada a necessidade de algumas adaptações estruturais dos Módulos Embarque® e MIX®, tais como:

- Tendo em vista que a CSN não é autossuficiente na produção de coque, foi necessário representar no Módulo Embarque®, a cadeia de fornecimento de coques adquiridos externamente, desde a aquisição até o seu consumo nos altos-fornos, passando pela representação dos rendimentos no peneiramento, que resultam em subprodutos consumidos em processos distintos - "small" coque e moinha de coque;

- Representação de restrições logísticas adicionais, tais como, (i) compatibilidade no transporte - entre dois redutores dentro da mesma carga e (ii) intervalo mínimo de recebimento entre cargas de mesma origem - em número de dias;

- Incorporação de metas e limites de qualidade, sendo que, na geração da solução, as metas podem ser violadas - segundo penalizações definidas pelo usuário-planejador, enquanto que os limites são tratados de forma estrita restrições fortes ou invioláveis);

- Possibilidade de simulação das políticas de compra e de abastecimento em função de hipóteses de variação do custo dos redutores, por exemplo, queda de preços à taxa de $2 \%$ por trimestre. Identificou-se, também, durante a fase de implantação da Solução UniSoma, a necessidade do desenvolvimento de 


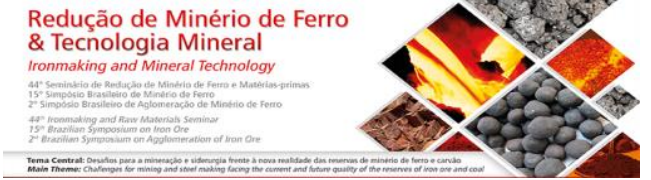

dois novos Módulos: o Módulo de Simulação de Fila de Navios e o Módulo de Programação de Transferência do Porto de Itaguaí, RJ, onde os redutores são recebidos, até a Usina Presidente Vargas, UPV, em Volta Redonda, RJ, onde a Usina está localizada.

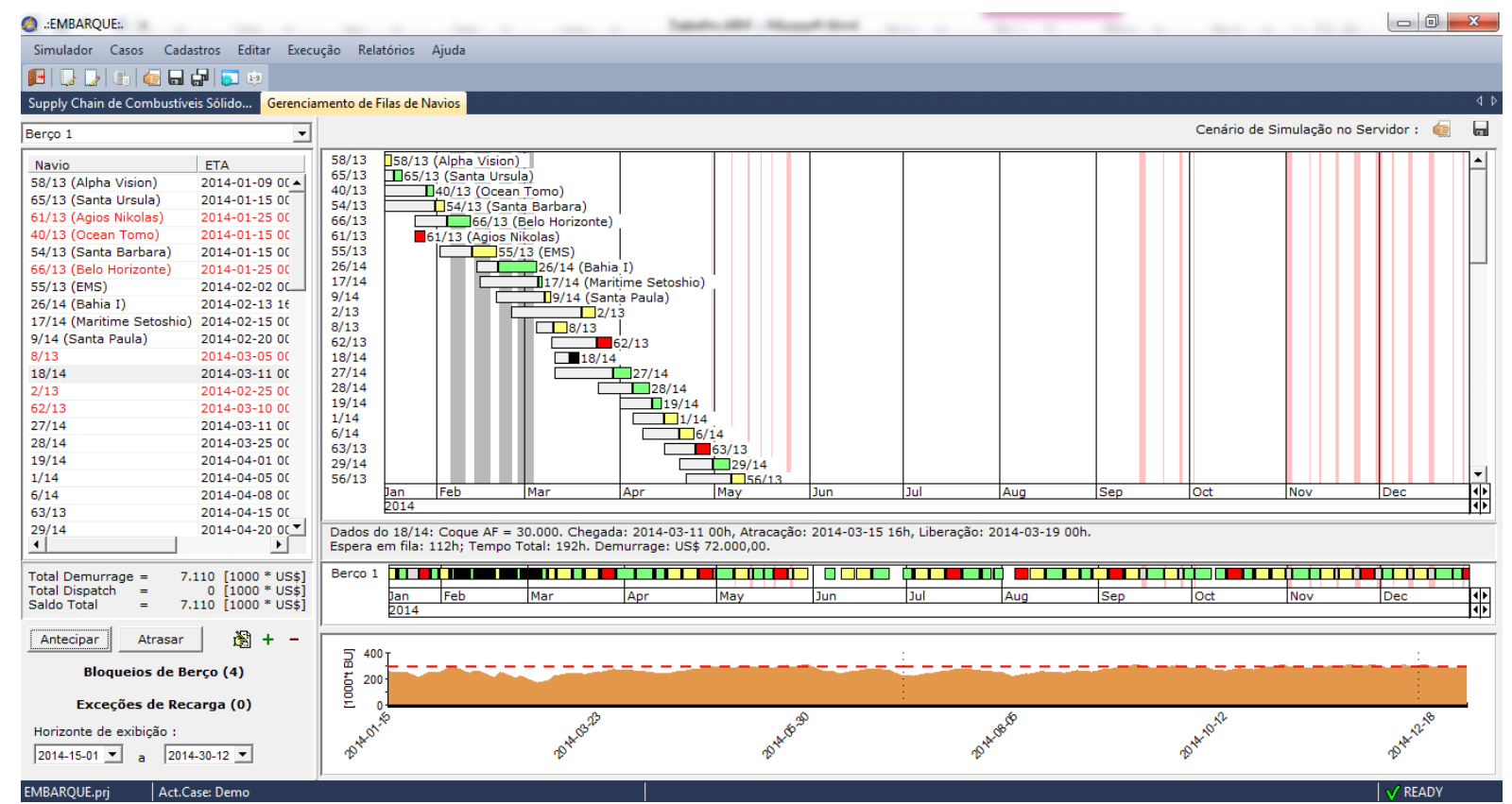

Figura 4: Módulo de Simulação de Fila de Navios

Através do Módulo de Simulação de Fila de Navios, ilustrado na Figura 4, é possível calcular com precisão as datas de atracação dos navios no porto em Itaguaí, RJ, em função da fila de descarga, que é formada por eventuais desvios na sincronização de chegada dos navios - programada pelo Módulo Embarque, bem como por interrupções na descarga, em função de problemas operacionais no pátio de armazenamento.

O Módulo de Transferência dá suporte à programação e reprogramação da transferência diária de redutores do pátio de estocagem do Porto para a Usina, segundo condicionantes operacionais relativos ao processo, tais como, as capacidades de transferência - em número de composições, e os requisitos de estoque de segurança na Usina.

A Solução é integrada com o ambiente de informações da CSN - ERP (SAP) e Sistemas Legados (MES e LIMS) para a leitura de inputs de natureza transacional, tratados pelos Módulos da Solução, como, por exemplo, os estoques e as qualidades dos diversos materiais.

Além disso, os Módulos também funcionam de forma integrada. O Embarque®, por exemplo, estabelece o Plano de Mistura, que servirá de Meta de Consumo para o MIX®. Assim, evita-se o uso indiscriminado, no curto prazo, de estoques "estratégicos" para médio e longo prazos. O módulo MIX®, por sua vez, define a Programação de Mistura, que será usada para fixar o Plano de Mistura de Curto Prazo - até 2 meses, no módulo Embarque®. A Figura 5 ilustra a integração funcional entre os dois Módulos. 


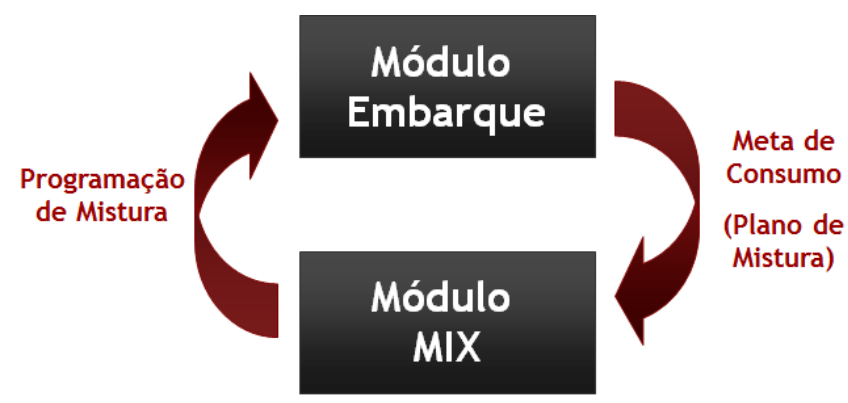

Figura 5: Integração entre os Módulos Embarque® e MIX®

Finalmente, vale observar que a Solução foi desenvolvida através do Software AIMMS, originalmente integrado ao CPLEX $\AA^{\circledR}$ da IBM ${ }^{\circledR}$, solver estado da arte para problemas de programação misto-inteira de grande porte, como aqueles tratados pelos Módulos da Solução, à exceção do Simulador de Filas. Já o deployment da Solução se dá através do AIMMS PRO - Publishing and Remote Optimization, Figura 6 , que é a última geração de frameworks cliente-servidor para sistemas de planejamento avançados utilizando AIMMS.

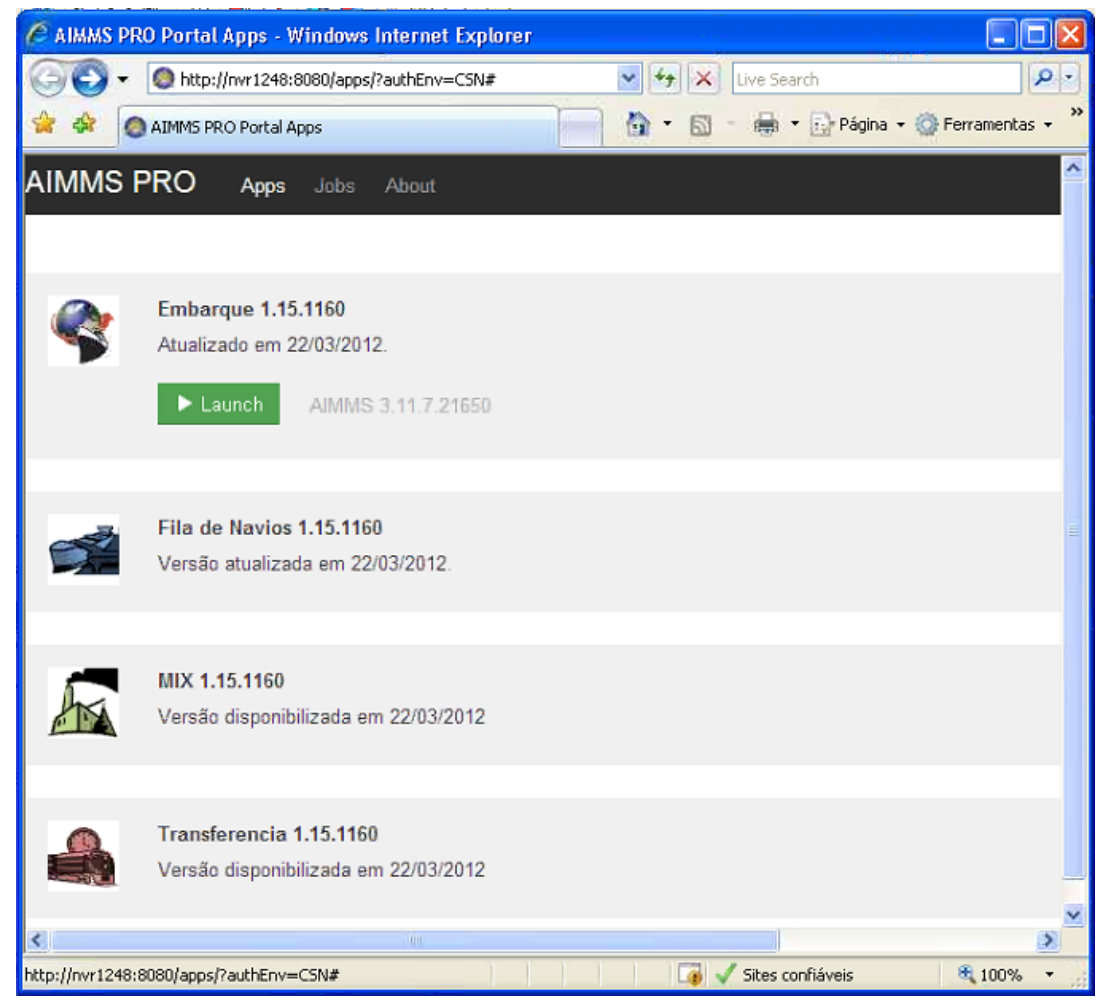

Figura 6: AIMMS PRO.

\section{RESULTADOS OBTIDOS}

Graças às visões integradas e otimizantes, os modelos que compõem a Solução são capazes de identificar oportunidades de ganhos econômicos, que normalmente não são percebidas pelos planejadores, que empregam os processos convencionais de gestão de redutores, empregando planilhas eletrônicas, dada a complexidade dos problemas em questão.

Estudos realizados para a seleção do mix ótimo de aquisição confirmaram as vantagens da utilização da nova ferramenta, em comparação ao processo convencional. Estudo de caso, tomando-se como referência a programação anual de 
embarque de redutores para 2011, mostrou que era possível reduzir o nível de estoque total e, simultaneamente, aumentar 0 estoque viável de carvões ("misturável"), em função do melhor balanceamento, resultando numa redução do custo CIF médio do mix de redutores da ordem de USS 4 - 10 / tonelada, além de melhorar a qualidade do coque. Isso representava uma redução dos custos de aquisição de redutores de cerca de US $\$ 7,0$ - 17,5 milhões / ano. Além disso, do ponto de vista tático, a Solução é capaz de gerar uma série de outros ganhos diretos, como, por exemplo, a redução do capital imobilizado, decorrente do melhor balanceamento do estoque viável - "misturável".

Em adição, a Solução fornece aos usuários uma maior visibilidade do que ocorrerá com a cadeia de fornecimento no futuro. $O$ Embarque ${ }^{\circledR}$, por exemplo, fornece uma previsão detalhada do estoque de todos os combustíveis ao longo do horizonte de planejamento, que demandaria um tempo relativamente longo para ser calculado através de planilha eletrônica, além dos riscos de erros de entrada de dados, que se constitui numa informação valiosa para o pessoal da área comercial, responsável pelo abastecimento.

Outro exemplo de benefício, decorrente do Módulo MIX®, é poder antecipar violações de qualidade, que poderão ocorrer no médio prazo, devido a atrasos no recebimento das cargas.

Os Módulos ainda são capazes de gerar soluções de "qualidade", otimizadas, em muito menor tempo do que aquele gasto pelos planejadores de redutores, utilizandose planilhas eletrônicas. Isso resultou em agilidade à atividade de reprogramação, tão fundamental nos tempos atuais de volatilidade nos mercados. Por outro lado, com a Solução, os planejadores passaram a atuar mais como analistas, propriamente ditos, do que como geradores de planos e programações manuais.

Finalmente, por todas as suas características, a Solução ampliou a capacidade analítica da empresa. O mesmo modelo desenvolvido para suportar a rotina de programação dos embarques e das misturas permite a rápida realização de estudos e análises que fogem à rotina diária, como, por exemplo, o impacto de um novo carvão ou da interrupção inesperada no fornecimento sobre a programação de embarque e, em últimas palavras, sobre o custo do coque.

\section{DESAFIOS NA IMPLANTAÇÃO}

Os desafios a destacar, enfrentados na implantação da Solução, foram de diversas naturezas. O primeiro desafio referiu-se ao número de parâmetros de entrada e à dificuldade em se coletar e cadastrar todas essas informações provenientes de áreas distintas - logística, operação e planejamento, com a qualidade mínima necessária exigida pelos modelos. Após essa etapa, foram feitas várias rodadas para validação do modelo, confrontando-se suas soluções com dados reais, que demandou bastante tempo e dedicação dos usuários, devido ao elevado volume de dados considerados nos modelos. Durante todo o período de implantação, foi fundamental a interação entre UniSoma e CSN, que possibilitou a introdução de vários ajustes e correções na Solução.

Outro desafio foi relativo à quebra de paradigma com relação ao processo convencional de programação, baseado em planilhas e fundamentado na separação dos problemas de determinação das programações de mistura e de abastecimento. Esse aspecto fundamental do Módulo Embarque® não foi facilmente apreendido logo no início da implantação, visto que o processo de resolução anterior era realizado em etapas: inicialmente determinava-se o plano de mistura ou "mistura anual" e, em seguida, gerava-se a programação de abastecimento, ou seja, cada

\footnotetext{
* Contribuição técnica ao $44^{\circ}$ Seminário de Redução de Minério de Ferro e Matérias-primas, 15은 Simpósio Brasileiro de Minério de Ferro e 2o Simpósio Brasileiro de Aglomeração de Minério de Ferro, 15 a 18 de setembro de 2014, Belo Horizonteo MG, Brasil.
} 
subproblema era resolvido através de uma planilha, de forma manual, de forma que o resultado final não era necessariamente ótimo do ponto de vista global.

\section{CONCLUSÃo}

A inteligência computacional embutida na Solução permite que a programação de abastecimento seja gerada de forma integrada ao plano de mistura de carvões, e não à programação de mistura. Mais do que isso, ela é capaz de determinar simultaneamente a combinação de programação de abastecimento e de plano de mistura, que por sua vez, também simultaneamente, minimiza o custo CIF total da mistura - volume e custo unitário, e maximiza o atendimento dos requisitos de qualidade dos carvões para mistura e para a qualidade final do coque.

Além dos resultados financeiros, da ordem de US\$ milhões, a formalização do conhecimento ad-hoc dos planejadores, disperso em planilhas e controles paralelos, em um sistema computacional "inteligente", representou para a CSN um avanço em termos de análise dos problemas e tomada de decisões, constituindo-se, também, num valioso instrumento do ponto de vista da governança corporativa.

Finalmente, vale observar que essa experiência reforçou a tese de que o sucesso na implantação de sistemas analíticos é fortemente dependente do envolvimento da alta administração das empresas, não só durante a fase de implantação, mas também durante a sua operacionalização e manutenção evolutiva, uma vez que só ela é capaz de dar respaldo aos envolvidos nesse processo, com relação ao tratamento dos riscos inerentes a um projeto dessa natureza.

\section{BIBLIOGRAFIA}

1 Solução UniSoma para o Supply Chain Planning de combustíveis sólidos, Proposta técnica e comercial, UniSoma Computação Ltda., Campinas, SP, Janeiro 2011. 